
planta. Horticultura Brasileira 27: 023-029.

\title{
Características de frutos do meloeiro variando número e posição de frutos na planta
}

\author{
Roberto Cleiton F de Queiroga; Mário Puiatti; Paulo Cezar R Fontes; Paulo Roberto Cecon \\ UFV-Deptos. Fitotecnia e Informática. 36570-000 Viçosa-MG; robertocleiton@ hotmail.com
}

\begin{abstract}
RESUMO
O trabalho foi conduzido em ambiente protegido, em área experimental da Universidade Federal de Viçosa, de 26/09/05 a 24/01/06, onde se objetivou avaliar a produtividade e a qualidade de frutos do meloeiro, variando número e posição de frutos na planta. Os tratamentos constaram de número de frutos por planta (1 e 2) e posição de fixação de frutos na planta (entre $5^{0}$ e $8^{0}$ nós e $15^{0}$ e $18^{0}$ nós). O delineamento experimental utilizado foi de blocos ao acaso no esquema fatorial 2 × 2, com 5 repetições. Utilizou-se a 'Coronado F1', variedade reticulatus do grupo Cantaloupe, cultivada em vasos plásticos de 11,5 $\mathrm{dm}^{3}$ preenchidos com fibra de coco comercial. Plantas com um fruto apresentaram maior duração do período de colheita, área foliar (AF) ( $5^{0}-8^{0}$ nó), massa média de frutos (MMF), reticulação da casca (RC), espessura da polpa (EP), comprimento (CF) e diâmetro de frutos (DF), sólidos solúveis totais (SST), açúcares solúveis totais (AST), açúcares não redutores (ANR) e menor produtividade comercial (PCF). A condução com frutos fixados entre os $15^{\circ}$ e $18^{\circ}$ nós, comparado a frutos fixados entre os $5^{0}$ e $8^{0}$ nós, proporcionou maior número de dias para iniciar e terminar a colheita, AF, MMF, PCF, EP, CF e DF (em plantas com 1 fruto), índice de maturação, AST, ANR e menor RC, acidez total titulável e concentração de açúcares redutores.
\end{abstract}

Palavras-chave: Cucumis melo L., relação fonte-dreno e rendimento.

\begin{abstract}
Yield and quality of muskmelon varying fruit number and position in the plant, in protected cultivation

The study was carried out in a greenhouse of the Universidade Federal de Viçosa, Minas Gerais State, Brazil, from 26/09/05 to 24/ $01 / 06$, to evaluate the yield and quality of the melon fruit, varying the number and position of fruits on the plant. The treatments consisted of fruit number per plant (1 and 2) and fruit position in the plant $\left(5^{\text {th }}-8^{\text {th }}\right.$ node and $15^{\text {th }}-18^{\text {th }}$ node $)$. A randomized block design was used, in a $2 \times 2$ factorial scheme, with 5 replications. The 'Coronado F1', variety reticulatus of the Cantaloupe group was cultivated in $11.5 \mathrm{dm}^{3}$ plastic pots with commercial coconut fiber. Plants with one fruit provided higher harvest period, leaf area (LA) ( $5^{\text {th }}-8^{\text {th }}$ node), fruit mean mass (MMF), net rind (NR), pulp thickness (PT), fruit length (LF), diameter (DF), total soluble solids, total soluble sugars (TSS), no reduced sugars (SNR) and smaller commercial fruit yield (PCF). Fruit fixation among the $15^{\text {th }}-18^{\text {th }}$ node led to more days to begin and to finish the harvest, LA, MMF, PCF, PT, LF and DF of fruits (in plants with 1 fruit), maturation index, TSS, and SNR and led to smaller NR and total titratable acidity and reduced sugar concentrations.
\end{abstract}

Keywords: Cucumis melo L., relationship source-sink and yield.

\section{(Recebido para publicação em 12 de junho de 2007; aceito em 22 de janeiro de 2009)}

(Received on June 12, 2007; accepted on January 22, 2009)

$\mathrm{O}$ cultivo do meloeiro na região sudeste do Brasil é indicado para o período primavera/verão em razão da elevada temperatura e dos níveis de radiação que favorecerem o crescimento da planta bem como dos frutos. Todavia, as constantes precipitações que ocorrem, sobretudo, no verão auxiliam na criação de condições climáticas favoráveis para a incidência de doenças que desfolham as plantas, resultando em baixa produtividade da cultura e qualidade dos frutos (Coelho et al., 2003). Dessa forma, o cultivo em ambiente protegido constitui alternativa para contornar estes problemas na época das águas. A cultura do melão também requer práticas culturais, tais como, raleio e fixação de frutos em posições pré-estabelecidas na planta. Essa prática cultural pode alterar a relação fonte-dreno e influenciar na produção da cultura.
A competição por assimilados entre drenos afeta a taxa de crescimento da planta e a fixação dos frutos do melão da variedade reticulatus, do grupo Cantaloupe são descritos como órgãos dominantes, em relação aos de crescimento vegetativo, e podem alterar a relação fonte-dreno durante o desenvolvimento da planta (Valantin et al., 1999). Em espécies como o tomateiro, a alocação de assimilados da fonte para os drenos depende principalmente, do número de frutos existentes na planta (Heuvelink, 1996), sendo que aumento no número de frutos eleva a fração de massa seca nos frutos (Andriolo \& Falcão, 2000).

O aumento de frutos fixados induz à competição por assimilados entre drenos e leva à diminuição do peso individual de fruto e do teor de sólidos solúveis totais da polpa em tomate (Bertin et al.,
1998) e em melões da variedade reticulatus pertencente ao grupo Cantaloupe (Costa et al., 2004; Valantin Morinson et al., 2006). Todavia, em melancia, segundo Seabra Júnior et al. (2003) o aumento de drenos na planta, apesar de reduzir a massa e o teor de sólidos totais dos frutos, elevou a produção da planta.

A posição do ramo produtivo na planta também pode influenciar a produtividade e a qualidade dos frutos. No tomateiro, Bertin (1995) observou que a força do dreno depende da posição da inflorescência no caule e da posição do fruto dentro da inflorescência. No meloeiro, especificamente na variedade reticulatus do grupo Cantaloupe, Maruyama et al. (2000), observaram que a posição do fruto não influenciou a massa média do fruto, o número médio de frutos por planta e o teor de sólidos 
solúveis totais quando estes foram conduzidos em ramos do $5^{0}$ ao $8^{0}$ nós, $9^{0}$ ao $11^{0}$ nós e $12^{0}$ ao $15^{0}$ nós; entretanto, a produção total por planta, foi menor quando os frutos foram fixados entre o $5^{0}$ e o $8^{0}$ nós. Também no meloeiro, com a variedade Inodorus, grupo Amarelo, Syn et al. (1991), observaram que houve diferença para a posição de fixação dos frutos com maior teor de sólidos solúveis totais obtidos em frutos fixados entre o $8^{0}$ e $10^{0}$ nós, quando comparados aqueles fixados entre o $4^{0}$ e $6^{0}$ nós, e entre o $6^{0}$ e $8^{0}$ nós. Por outro lado, em melancia, Seabra Júnior et al. (2003) observaram maior teor de sólidos solúveis totais na posição de fixação do fruto entre o $8^{0}$ e $11^{0}$ nós, quando comparado aos frutos fixados entre o $13^{0}$ e $16^{0}$ nós sem, no entanto, apresentar efeito em relação a massa média do fruto. Portanto, é possível que a poda do meloeiro possa interferir na produtividade e qualidade dos frutos, com resposta diferente entre cultivares.

O objetivo deste trabalho foi avaliar a produtividade e a qualidade de frutos de meloeiro variando o número e a posição de frutos na planta, em ambiente protegido.

\section{MATERIAL E MÉTODOS}

O experimento foi conduzido em ambiente protegido, na Universidade $\mathrm{Fe}$ deral de Viçosa, de 26/09/05 a 24/01/06. A casa de vegetação do tipo capela foi coberta com filme plástico PEBD de 0,15 $\mathrm{mm}$ de espessura e apresentava as dimensões de 40 x 8 m. Quando necessário se realizou o manejo para fechamento das cortinas frontais e laterais durante a noite e parte do dia. A temperatura e a umidade relativa do ar no interior do ambiente protegido, durante o período experimental, registradas por termohigrômetro digital (modelo HT210), colocados à altura do dossel das plantas à medida que estas foram crescendo, apresentaram valores de mínima e de máxima de 17,2 e $37,3^{\circ} \mathrm{C}$ e de 39,4 e $94,9 \%$, respectivamente. O delineamento experimental utilizado foi de blocos casualizados, em esquema fatorial $2 \times 2$, com cinco repetições. Os tratamentos foram constituídos de número de frutos por planta (1 e 2) e de posição de fixação desses frutos na planta (entre $5^{0}$ e $8^{0}$ nós e entre $15^{\circ}$ e $18^{0}$ nós). O espaçamento adotado foi de 1,0 x 0,5 m. A parcela útil constou de uma fileira com oito plantas. Utilizou-se a 'Coronado F1', variedade reticulatus pertencente ao grupo Cantaloupe, que apresenta frutos com pequena cavidade interna, casca rendilhada, polpa salmão e alto teor de sólidos solúveis. A semeadura foi realizada em 26/09/05, em bandejas de poliestireno extendido com 128 células, preenchida com substrato agrícola comercial que constituía uma mistura de húmus e vermiculita na proporção de 2:1, e o transplante 22 dias após a semeadura, com as mudas apresentando a segunda folha expandida.

As plantas foram cultivadas em vasos plásticos pretos de $11,5 \mathrm{dm}^{3}$, preenchidos com substrato à base de fibra de coco, Golden Mix tipo 98, contendo uma planta cada. O substrato possui $50 \%$ de substrato de textura grosseira e $50 \%$ de textura granulada apresentando, em média, 98\% de matéria orgânica, 95\% de porosidade total, $35 \%$ de capacidade de aeração, $400 \mathrm{~mL} \mathrm{~L}^{-1}$ de capacidade de retenção de água, $0,9 \mathrm{dS} \mathrm{m}^{-1}$ de condutividade elétrica e 5,9 de pH.

A irrigação foi realizada diariamente, através de sistema localizado por gotejamento. Os emissores dos tubos de gotejamento tinham espaçamento de $0,5 \mathrm{~m}$ e vazão de $2,3 \mathrm{~L} \mathrm{~h}^{-1}$. Aplicou-se a quantidade de água de $96,3 \mathrm{~L}_{\text {planta }}{ }^{-1}$ no decorrer do ciclo da cultura. Na fase inicial de crescimento (28 dias) foram aplicados 21,5 L planta $^{-1}$, em quatro aplicações diárias; na fase de florescimento e frutificação (60 dias) foram aplicados 70,2 L planta ${ }^{-1}$, em seis irrigações durante o dia e na fase de colheita (12 dias), foram aplicados 4,6 $\mathrm{L}_{\text {planta }}{ }^{-1}$ em duas aplicações ao dia. A duração de cada irrigação foi de 5 minutos, de forma a não haver drenagem e perda da solução nutritiva.

As adubações de cobertura foram realizadas diariamente, via fertirrigação, com base nas recomendações de Castellane \& Araújo (1994), em relação aos macronutrientes e Furlani et al. (1999), em relação aos micronutrientes e apresentou a seguinte concentração: $165 ; 150 ; 133 ; 100 ; 0,3 ; 2,2 ; 0,6,0,3,0,05 \mathrm{e}$ $0,05 \mathrm{mg} \mathrm{dm}^{-3} \mathrm{de} \mathrm{K}, \mathrm{Ca}, \mathrm{Mg}, \mathrm{S}, \mathrm{B}, \mathrm{Fe}, \mathrm{Mn}$,
Zn, Cu e Mo, com modificações para $\mathrm{Ne}$ $\mathrm{P}$ que foi de 200 e $160 \mathrm{mg} \mathrm{dm}^{-3}$, respectivamente.

As plantas foram conduzidas verticalmente, em haste única, com uso de fitilhos fixados na base das plantas e em bambu colocado na horizontal, a 1,80 m do solo. A poda da haste principal foi realizada no $28^{0}$ nó. Nos ramos secundários quando foram conduzidos dois frutos por planta, estes foram fixados em hastes diferentes dentro da faixa estabelecida pelo tratamento, com a poda realizada duas folhas após a fixação dos frutos. Todas as demais ramificações e frutos foram eliminados. Para auxiliar na polinização, foram colocadas duas colméias de abelhas melíferas na parte externa do ambiente protegido durante o período de florescimento. Quando necessário, procedeu-se o controle fitossanitário com fungicidas e inseticidas registrados para cultura, aplicando-se a calda no final da tarde, sobretudo no período de floração e frutificação.

A colheita iniciou-se em 06/01/06, 103 dias após a semeadura (DAS), quando os frutos apresentavam a formação da camada de abscisão. Avaliaram-se as seguintes características em amostra de 20 plantas e/ou frutos por tratamento nos cinco blocos: a) tempo para o início da colheita; b) duração da colheita; c) duração do ciclo da cultura; d) área foliar da planta, avaliada em aparelho Li-3000, marca LI-COR; e) massa média de fruto; f) produtividade comercial; g) reticulação da casca, atribuindo-se notas de $1(0 \%), 2(25 \%), 3(50 \%), 4(75 \%)$ e 5 (100\% da superfície reticulada); h) espessura da polpa, avaliada na região equatorial, após a secção do fruto no sentido longitudinal; i) comprimento e diâmetro do fruto, medidos no sentido longitudinal e transversal do fruto; $\mathrm{j}$ ) índice de formato determinado pela razão entre comprimento e diâmetro de frutos; k) teor de sólidos solúveis totais (TSS) e acidez total titulável (ATT) em amostras de fatias de frutos retiradas no sentido longitudinal, e homogeneizadas em liquidificador para a obtenção do suco. O TSS foi determinado por meio de refratômetro de mesa, modelo ATAGO 3 T, obtendo-se os valores em \%, corrigidos a $20^{\circ} \mathrm{C}$. Para ATT, utilizou-se uma 
alíquota de $10 \mathrm{~mL}$ de suco, em duplicata, à qual foi adicionado $40 \mathrm{~mL}$ de água destilada e três gotas do indicador fenolftaleína alcoólica a $1 \%$ e, em seguida, procedeu-se a titulação com solução de $\mathrm{NaOH} 0,1 \mathrm{~N}$ até o ponto de viragem, com os resultados expressos em porcentagem de ácido cítrico; índice de maturação por meio da razão SST/ATT; 1) açúcares solúveis totais (AST), quantificados na mesma amostra, por meio da reação com Antrona, conforme Yemm \& Willis (1954) e os açúcares redutores (AR), pelo método do DNS (Miller, 1959). Os açúcares não redutores foram determinados por diferença entre AST e AR. Consideraram-se comerciais, frutos uniformes quanto à cor, com bom rendilhamento de casca, sem deformações, murchamento, rachaduras, sinais de podridão, de ataque de insetos pragas e de danos mecânicos.

Os dados foram submetidos às análises de variância e teste de Tukey a 5\% de probabilidade para comparação das médias dos tratamentos.

\section{RESULTADOS E DISCUSSÃO}

Houve efeito significativo da interação para o número de frutos por planta x posição de fixação de frutos na planta sobre o início da colheita (IC), ciclo da cultura (CC), área foliar da planta (AF), espessura de polpa (EP), comprimento (CF) e diâmetro de fruto (DF); apenas do número de frutos por planta sobre a duração da colheita (DC) e sólidos solúveis totais (SST). Houve efeito apenas de posição de fixação do fruto sob a acidez total titulável (ATT), índice de maturação (IM) e açúcares redutores (AR) e do número de frutos e da posição de fixação dos frutos sobre a massa média de frutos (MMF), produtividade comercial de frutos (PCF), reticulação de casca (RC), açúcares solúveis totais (AST) e açúcares não redutores (ANR) (Tabelas 1, 2, 3, 4 e 5).

Em comparação aos frutos fixados entre o $15^{0} \mathrm{e} 18^{0}$ nós, plantas com frutos fixados entre o $5^{0}$ e $8^{0}$ nós tiveram o IC antecipado em 11,2 e 8,2 dias e o CC encurtado em 11 e 8 dias, em plantas com um e dois frutos, respectivamente (Tabela 1). Ramificações laterais são as que emitem as flores hermafroditas; em razão dos ramos la-

Tabela 1. Início da colheita (IC), duração da colheita (DC) e ciclo da cultura (CC) de meloeiro cultivado em ambiente protegido em função do número e posição do fruto na planta (beginning of the harvest (IC), harvest duration (DC) and cultivation cycle (CC) in muskmelon cultivated in greenhouse in function of the number and position of the fruit in the plant). Viçosa, UFV, 2006.

\begin{tabular}{|c|c|c|c|c|c|}
\hline \multirow{2}{*}{$\mathrm{N}^{\circ}$ de frutos } & \multicolumn{2}{|c|}{ IC (dias) } & \multirow{2}{*}{ DC (dias) } & \multicolumn{2}{|c|}{ CC (dias) } \\
\hline & $5^{\circ}-8^{\circ}$ nó & $15^{\circ}-18^{\circ}$ nó & & $5^{\circ}-8^{\circ}$ nó & $15^{\circ}-18^{\circ}$ nó \\
\hline 1 & $103,6 \mathrm{a} \mathrm{B}^{1}$ & 114,8 a $A$ & $9,5 \mathrm{a}$ & 113,0 a $B$ & 124,0 a $A$ \\
\hline 2 & 104,0 a B & 112,2 b A & $8,0 \mathrm{~b}$ & 112,0 a B & $120,0 \mathrm{~b} \mathrm{~A}$ \\
\hline $5^{\circ}-8^{\circ}$ nó & \multicolumn{2}{|r|}{-} & 9,0 a & \multicolumn{2}{|r|}{-} \\
\hline $15^{\circ}-18^{\circ}$ nó & \multicolumn{2}{|r|}{-} & $8,5 \mathrm{a}$ & \multicolumn{2}{|r|}{-} \\
\hline$\overline{\mathrm{CV}(\%)}$ & \multicolumn{2}{|c|}{1,01} & 8,08 & \multicolumn{2}{|c|}{0,70} \\
\hline
\end{tabular}

${ }^{1}$ Nas colunas, as médias seguidas pela mesma letra minúscula e nas linhas pela mesma letra maiúscula, não diferem entre sí pelo teste Tukey ao nível de 5\% de probabilidade (in columns, means followed by the same small letters and in the lines by the same capital letters are not significantly different through the Tukey test, at the level of $5 \%$ probability).

Tabela 2. Área foliar (AF), massa média de frutos (MMF) e produtividade comercial de frutos (PCM) de meloeiro cultivados em ambiente protegido em função do número e posição do fruto na planta (leaf area (AF), mass mean of fruits (MMF) and commercial productivity of fruits $(\mathrm{PCF})$ in muskmelon cultivated in greenhouse in function of the number and position of the fruit in the plant). Viçosa, UFV, 2006.

\begin{tabular}{|c|c|c|c|c|}
\hline \multirow{2}{*}{$\mathrm{N}^{\circ}$ de frutos } & \multicolumn{2}{|c|}{$\mathrm{AF}\left(\mathrm{cm}^{2}\right.$ planta $\left.^{-1}\right)$} & \multirow{2}{*}{ MMF (g fruto ${ }^{-1}$ ) } & \multirow[t]{2}{*}{ PCF (Mg ha $\left.{ }^{-1}\right)$} \\
\hline & $5^{\circ}-8^{\circ}$ nó & $15^{\circ}-18^{\circ}$ nó & & \\
\hline$\overline{1}$ & $4386,2 \mathrm{a} \mathrm{B}^{1}$ & 5361,6 a $A$ & $980,3 \mathrm{a}$ & $19,61 \mathrm{~b}$ \\
\hline 2 & 3018,4 b B & 5118,6 a $A$ & $791,3 \mathrm{~b}$ & $31,65 \mathrm{a}$ \\
\hline $5^{\circ}-8^{\circ}$ nó & \multicolumn{2}{|c|}{-} & $847,9 \mathrm{~b}$ & $24,60 \mathrm{~b}$ \\
\hline $15^{\circ}-18^{\circ}$ nó & \multicolumn{2}{|c|}{-} & 923,7 a & $26,67 \mathrm{a}$ \\
\hline$\overline{C V}(\%)$ & \multicolumn{2}{|c|}{9,60} & 4,65 & 5,55 \\
\hline
\end{tabular}

${ }^{1}$ Nas colunas, as médias seguidas pela mesma letra minúscula e nas linhas pela mesma letra maiúscula, não diferem entre sí pelo teste Tukey ao nível de 5\% de probabilidade (in columns, means followed by the same small letters and in the lines by the same capital letters are not significantly different through Tukey test at the level of 5\% probability).

terais do $5^{0} \mathrm{e} 8^{0}$ nós saírem primeiro, quando comparado aos ramos laterais do $15^{0} \mathrm{e}$ $18^{0}$ nós, ocorreu antecipação do IC e redução do CC. Por outro lado, nas plantas com apenas um fruto, comparado a plantas com dois frutos, observou-se atraso de 2,6 e 4,0 dias para o IC e CC, respectivamente, somente quando os frutos foram fixados entre o $15^{0}$ e $18^{0}$ nós (Tabela 1). Desta forma, a maior AF disponível por fruto, em plantas com apenas um fruto, produziu maiores quantidades de fotoassimilados, melhor aproveitados pelo mesmo, aumentando seu crescimento e o tempo de permanência na planta, para 1,5 dia na DC. Este fato pode ser benéfico para a qualidade dos frutos, já que este depende dos carboidratos translocados da parte aérea, uma vez que não armazena amido que poderia ser degradado aumentando o teor de açúcar após a colheita (Hubbard \& Pharr, 1990).

Em plantas com um fruto, apesar da maior competição entre fonte e dreno, para frutos fixados próximo a base da planta, tem-se redução do CC. Desta forma, pode-se aumentar a eficiência de uso do ambiente protegido e minimizar problemas com doenças que aparecem com mais facilidade em plantas senescentes. Portanto, na decisão de se antecipar a colheita deve-se levar em consideração a qualidade dos frutos e não apenas o preço, o rendimento e a redução de custos com a condução de plantas (Martins et al., 1998).

Plantas com apenas um fruto apresentaram maior AF do que com dois frutos somente na posição de fixação do fruto do $5^{0}$ e $8^{0}$ nós (Tabela 2), o que foi devido à menor competição por assimilados entre órgãos vegetativo e reprodutivo, ou seja, a força do dreno foi menor em plantas com um fruto e os assimilados restantes estariam sendo utilizados na expansão de folhas. Quando fixados entre o $15^{0}$ e $18^{0}$ nós, comparado aos do $5^{0}$ e $8^{0}$ nós, a AF também foi 
Tabela 3. Reticulação da casca (RC), espessura da polpa (EP) e comprimento do fruto (CF) de meloeiro cultivado em ambiente protegido em função do número e posição do fruto na planta (netted rind (NR), pulp thickness (PT) and fruit length in muskmelon cultivated in greenhouse in function of the number and position of the fruit in the plant). Viçosa, UFV, 2006.

\begin{tabular}{|c|c|c|c|c|c|}
\hline \multirow{2}{*}{$\mathrm{N}^{\circ}$ de frutos } & \multirow{2}{*}{ RC } & \multicolumn{2}{|c|}{$\mathrm{EP}(\mathrm{cm})$} & \multicolumn{2}{|c|}{ CF (cm) } \\
\hline & & $5^{\circ}-8^{\circ}$ nó & $15^{\circ}-18^{\circ}$ nó & $5^{\circ}-8^{\circ}$ nó & $15^{\circ}-18^{\circ}$ nó \\
\hline 1 & $4,9 a^{1}$ & 3,1 a $B$ & 3,4 a $\mathrm{A}$ & 13,0 a B & 13,7 a $A$ \\
\hline 2 & $3,8 \mathrm{~b}$ & $2,9 \mathrm{~b} \mathrm{~A}$ & $2,6 \mathrm{~b} \mathrm{~B}$ & $12,5 \mathrm{~b} \mathrm{~A}$ & 11,5 b B \\
\hline $5^{\circ}-8^{\circ}$ nó & $4,5 \mathrm{a}$ & \multicolumn{2}{|c|}{ - } & \multicolumn{2}{|r|}{-} \\
\hline $15^{\circ}-18^{\circ}$ nó & $4,2 \mathrm{~b}$ & \multicolumn{2}{|c|}{-} & \multicolumn{2}{|r|}{-} \\
\hline $\mathrm{CV}(\%)$ & 6,44 & \multicolumn{2}{|c|}{2,94} & \multicolumn{2}{|c|}{2,40} \\
\hline
\end{tabular}

${ }^{1}$ Nas colunas, as médias seguidas pela mesma letra minúscula e nas linhas pela mesma letra maiúscula, não diferem entre sí pelo teste Tukey ao nível de 5\% de probabilidade (in columns, means followed by the same small letters and in the lines by the same capital letters are not significantly different through Tukey test at the level of $5 \%$ probability).

Tabela 4. Diâmetro do fruto (DF), índice de formato do fruto (IFF), sólidos solúveis totais (SST) e acidez total titulável (ATT) de frutos de meloeiro cultivados em ambiente protegido em função do número e posição do fruto na planta (fruit diameter (DF), fruit format index (IFF), total soluble solids (SST) and total tritratable acidity (ATT) in fruit of muskmelon cultivated in greenhouse in function of the number and position of the fruit in the plant). Viçosa, UFV, 2006.

\begin{tabular}{|c|c|c|c|c|c|}
\hline \multirow{2}{*}{$\mathbf{N}^{\circ}$ de frutos } & \multicolumn{2}{|c|}{ DF (cm) } & \multirow{2}{*}{ IFF } & \multirow{2}{*}{ SST (\%) } & \multirow{2}{*}{$\begin{array}{c}\text { ATT (\% ácido } \\
\text { cítrico) }\end{array}$} \\
\hline & $5^{\circ}-8^{\circ}$ nó & $15^{\circ}-18^{\circ}$ nó & & & \\
\hline 1 & 11,5 a B & 12,0 a $A^{1}$ & $1,1 \mathrm{a}$ & $12,7 \mathrm{a}$ & $0,082 \mathrm{a}$ \\
\hline 2 & $11,0 \mathrm{~b} \mathrm{~A}$ & 10,5 b B & $1,1 \mathrm{a}$ & $11,9 \mathrm{~b}$ & $0,082 \mathrm{a}$ \\
\hline $5^{\circ}-8^{\circ}$ nó & \multicolumn{2}{|r|}{-} & $1,1 \mathrm{a}$ & $12,1 \mathrm{a}$ & $0,095 a$ \\
\hline $15^{\circ}-18^{\circ}$ nó & \multicolumn{2}{|r|}{ - } & $1,1 \mathrm{a}$ & $12,4 \mathrm{a}$ & $0,070 \mathrm{~b}$ \\
\hline CV (\%) & \multicolumn{2}{|c|}{1,67} & 2,91 & 2,12 & 10,10 \\
\hline
\end{tabular}

${ }^{1}$ Nas colunas, as médias seguidas pela mesma letra minúscula e nas linhas pela mesma letra maiúscula, não diferem entre si pelo teste Tukey ao nível de 5\% de probabilidade (in the columns, means followed by the same small letters and in the lines by the same capital letters are not significantly different trough Tukey test at the level of 5\% probability).

maior; com o atraso da frutificação, a planta já havia formado a AF mais próxima da observada na colheita, não alterando de forma significativa, com a força exercida pelo dreno. Segundo El Keblawy \& Lowett Doust (1996), a redução de drenos na planta favorece o crescimento vegetativo, com maior taxa de produção de folhas, elevando, a AF da planta. Purquerio et al. (2003) não observaram diferença na AF entre plantas que fixaram dois e quatro frutos, e observaram tendência de redução da AF à medida que o número de frutos por planta variou de dois para plantas com fixação livre de frutos.

Condução das plantas com dois frutos, e quando fixados entre o $5^{0}$ e $8^{0}$ nós, reduziu a $\mathrm{MMF}$, todavia incrementou a PCF (Tabela 2). A menor MMF em plantas com dois frutos foi devido à menor $\mathrm{AF}$ disponível por fruto; entretanto, nestas plantas obteve-se maior PCF em função do maior número de frutos por planta e, conseqüentemente, por área. Para outras hortaliças de frutos, como tomateiro (Bertin et al., 1998), melancia (Seabra Júnior et al., 2003) e meloeiro (Valantin Morinson et al., 2006), o aumento do número de frutos por planta contribui para redução da $\mathrm{MMF}$ devido à competição por assimilados. No meloeiro, o número de frutos por planta e a MMF, são características determinantes na produtividade da cultura. Long et al. (2004), concluíram que a prática do raleio no meloeiro altera a produtividade da cultura, uma vez que, mesmo incrementando a MMF, houve redução na PCF de 31 para $20 \mathrm{t} \mathrm{ha}^{-1}$ ao reduzir de dois para um fruto al. (2006) observaram maior produtividade em plantas com dois frutos $\left(76,8 \mathrm{tha}^{-1}\right)$ do que com apenas um fruto $\left(42,9 \mathrm{tha}^{-1}\right)$.

Obteve-se maior AF, MMF e PCF quando frutos foram fixados entre $15^{\circ} \mathrm{e}$ $18^{0}$ nós, comparado a frutos fixados enpor planta. Também em meloeiro, Fagan et tre o $5^{0}$ e $8^{0}$ nós (Tabela 2). Atraso na fixação dos frutos proporcionou mais assimilados para formação da AF disponibilizando, conseqüentemente, mais assimilados para o crescimento do fruto (MMF), elevando a PCF. Long et al. (2004), ao atrasar a polinização no meloeiro, verificaram elevação na biomassa vegetativa da planta com maior MMF. Maruyama et al. (2000) também obtiveram maior produtividade em plantas de meloeiro com frutos fixados entre o $12^{\circ} \mathrm{e}$ $15^{0}$ nós do que fixados entre o $5^{0}$ e $8^{0}$ nós. A maior competição entre órgãos vegetativo e reprodutivo ocorre quando da fixação de frutos próximos à base da planta, comprometendo o crescimento da planta e, conseqüentemente, a produção total, principalmente se a planta apresentar AF insuficiente no momento em que os frutos forem fixados (Seabra Júnior et al., 2003). Todavia em melancia, Seabra Júnior et al. (2003) não observaram diferenças significativas quanto à $\mathrm{MMF}$ quando fixados nas posições entre o $8^{0}$ e $11^{0}$ nós e $13^{\circ}$ e $16^{0}$ nós, indicando haver comportamento diferencial entre espécies.

A redução do número de frutos por planta proporcionou aumento da relação fonte-dreno e resultou em mais fotoassimilados disponíveis para o crescimento dos frutos, manifestado em termos de reticulação da casca (RC), espessura da polpa (EP), comprimento $(\mathrm{CF})$ e diâmetro do fruto (DF), independe da posição de fixação do fruto (Tabelas $3 \mathrm{e}$ 4). Também frutos fixados entre o $5^{0}$ e $8^{0}$ nós apresentaram maior RC, comparado aos frutos do $15^{0}$ e $18^{0}$ nós, em razão de serem drenos preferenciais elevando a taxa de crescimento, principalmente em plantas com dois frutos, onde obtevese maior EP, CF e DF em frutos advindos do $5^{0}$ e $8^{0}$ nós; todavia, na condução de apenas um fruto por planta obteve-se maior EP, CF e DF quando fixados entre o $15^{0}$ e $18^{0}$ nós (Tabelas 3 e 4 ).

Em condições de maior competição por assimilados como é o caso de plantas conduzidas com dois frutos, observou-se baixa qualidade de frutos quanto ao aspecto visual do rendilhamento (RC). De acordo com Keren Keirserman et al. (2004), a RC está relacionada com a taxa de crescimento dos frutos e é devida à elevação da tensão de ruptura na 
casca levando a rachaduras, multiplicação das células da periderme e enchimento das rachaduras com massa de células com paredes suberizadas que se estendem acima da superfície do fruto.

A condução da planta com maior relação fonte-dreno (1 fruto fixado entre o $15^{0}-18^{0}$ nós) proporcionou maior EP (Tabela 3), em razão do maior crescimento do fruto, conforme obtido na MMF. Quando aumentou a competição na planta pelo incremento do número de frutos por planta, observou-se menor EP devido à maior competição por assimilados entre frutos e parte vegetativa. Em plantas com dois frutos, aqueles advindos do $5^{0}$ ao $8^{0}$ nós, comparados aos do $15^{0}$ ao $18^{0}$ nós, registraram maior EP em função do aumento do crescimento do fruto em termos de CF e DF. Monteiro \& Mexia (1988), também observaram aumento do tamanho do fruto à medida que reduzia o número de frutos por planta. Coelho et al. (2003) afirmam que o aumento da EP constitui-se em importante atributo de qualidade por se tratar da parte comestível do fruto do meloeiro. Purquerio \& Cecílio Filho (2005) observaram em plantas com dois frutos EP de $3,1 \mathrm{~cm}$, valor superior ao obtido neste trabalho, que foi de $2,8 \mathrm{~cm}$, independente da posição de fixação do fruto na planta.

Quanto ao CF e DF, Valantin Morinson et al. (2006) afirmam que a fixação dos frutos na planta influencia a taxa de crescimento e o tamanho final, uma vez que, toda a expansão celular ocorre após a antese e a divisão celular continua em baixa taxa, com o número de células no final da antese sendo um fator chave que contribui para a variação no tamanho final dos frutos, principalmente, por causa de sua influencia para atrair os assimilados após a polinização. Os resultados deste trabalho corroboram com os obtidos por Seabra Júnior et al. (2003) em melancia e Fagan et al. (2006) no meloeiro, em que obtiveram maior CF e DF em plantas conduzidas com apenas um fruto. Ainda, de acordo com Seabra Júnior et al. (2003), apenas o CF foi influenciado pela posição de fixação do fruto, verificando que na posição mais elevada na planta $\left(13^{0}\right.$ ao $16^{0}$ nós) e em plantas conduzidas com dois frutos, estes apresentaram menor índice de formato de frutos (IFF =

Tabela 5. Índice de maturação (IM), açúcares solúveis totais (AST), açúcares redutores (AR) e açúcares não redutores (ANR) de frutos de meloeiro cultivados em ambiente protegido em função do número e posição do fruto na planta (maturation index (IM), total soluble sugars (SST), reducer sugars (AR) and no reducer sugars (ANR) in muskmelon cultivated in greenhouse in function of the number and position of the fruit in the plant). Viçosa, UFV, 2006.

\begin{tabular}{lcccc}
\hline $\mathbf{N}^{\circ}$ de frutos & $\begin{array}{c}\text { Índice de } \\
\text { maturação }\end{array}$ & $\begin{array}{c}\text { Açúcares } \\
\text { solúveis totais } \\
(\%)\end{array}$ & $\begin{array}{c}\text { Açúcares } \\
\text { redutores (\%) }\end{array}$ & $\begin{array}{c}\text { Açúcares não } \\
\text { redutores (\%) }\end{array}$ \\
\hline 1 & $159,4 \mathrm{a}^{1}$ & $10,6 \mathrm{a}$ & $3,7 \mathrm{a}$ & $6,9 \mathrm{a}$ \\
2 & $150,3 \mathrm{a}$ & $9,5 \mathrm{~b}$ & $3,6 \mathrm{a}$ & $6,0 \mathrm{~b}$ \\
$5^{\circ}-8^{\circ}$ nó & $130,6 \mathrm{~b}$ & $9,6 \mathrm{~b}$ & $3,9 \mathrm{a}$ & $5,7 \mathrm{~b}$ \\
$15^{\circ}-18^{\circ}$ nó & $179,1 \mathrm{a}$ & $10,7 \mathrm{a}$ & $3,4 \mathrm{~b}$ & $7,3 \mathrm{a}$ \\
\hline $\mathrm{CV}(\%)$ & 13,51 & 10,23 & 7,63 & 15,00 \\
\hline
\end{tabular}

${ }^{1}$ Nas colunas, as médias seguidas pela mesma letra minúscula e nas linhas pela mesma letra maiúscula, não diferem entre sí pelo teste Tukey ao nível de 5\% de probabilidade (in columns, means followed by the same small letters and in the lines by the same capital letters are not significantly different by test Tukey at the level of 5\% probability).

CF/DF). Neste trabalho, o IFF não foi alterado em função do número e da posição de fixação do fruto na planta, pois, tanto o CF quanto o DF alteraram de forma proporcional, atribuindo este fato, à característica do híbrido que apresentar formato esférico. Em melão, o IFF é importante na classificação e padronização, podendo determinar a aceitação e valorização do produto para determinados mercados. Também define a embalagem e o arranjo dos frutos no seu interior; nesse aspecto, frutos com IFF próximo de um são preferidos, pois acima (alongados) e abaixo (achatados) deste valor comprometem a sua acomodação nas embalagens (Purquerio \& Cecílio Filho, 2005). De acordo com os mesmo autores, não houve diferenças significativas no IFF do meloeiro em função do aumento do número de frutos por planta de dois para quatro.

Plantas conduzidas com apenas um fruto apresentaram maior valor de sólidos solúveis totais (SST), açúcares solúveis totais (AST) e açúcares não-redutores (ANR); por outro lado, frutos fixados entre o $5^{0}$ e $8^{0}$ nós apresentaram maior acidez total titulável (ATT) e a concentração de açúcares redutores (AR) e menores índice de maturação (IM), AST e ANR (Tabela 4 e 5).

De acordo com Valantin Morinson et al. (2006), o teor de SST é um indicador direto da quantidade de sacarose nos tecidos do fruto do melão. Long et al. (2004) atribuem o maior teor de SST observados em frutos de plantas conduzidas com apenas um fruto a maior disponibilidade e aporte de fotoassimilados para o fruto em razão da maior AF por fruto. Estes autores observaram valores de SST de 9,0 e de $7,8 \%$ quando as plantas foram conduzidas com um e dois frutos, respectivamente. Costa et al. (2004), também observaram que a competição por assimilados reduziu o teor de SST. Quanto a posição de fixação do fruto na planta, observou-se que o SST apresentou resposta semelhante ao obtido por Maruyama et al. (2000), os quais não observaram variações significativas no SST nas posições de fixação do fruto $\left(5^{0}\right.$ e $8^{0}, 9^{0}$ e $11^{0}$ e $12^{0}$ e $15^{0}$ nós) nos híbridos Bônus $\mathrm{n}^{0} 2$ e D. Carlos. Aparentemente, este acúmulo de SST em determinadas posições na planta pode estar relacionado à cultivar, uma vez que Syn et al. (1991), no meloeiro, encontraram maior TSS em 'House-Euncheon' do $8^{0}$ ao $10^{\circ}$ nós em relação a posições do $4^{0}$ e $6^{0}$ nós e do $6^{0}$ ao $8^{0}$ nós, porém não havendo diferença significativa no híbrido Keumssaragi, em função das várias faixas de fixação testadas. Tais diferenças podem ser devidas às cultivares, práticas de manejo de plantas, condições edafoclimáticas distintas, que alteram a taxa de crescimento das plantas e a partição de assimilados entre os órgãos da planta e influenciando na acumulação de açúcar no fruto.

Em melões, em geral, a ATT varia de 0,05 a 0,35\% de ácido cítrico (Menlinger \& Pastenak, 1992). Neste trabalho, as médias situaram-se dentro do limite, e reduziram nos frutos fixados entre o $15^{\circ}$ 
e $18^{0}$ nós, apesar da falta de diferença no SST. Costa et al. (2004) e Purquerio \& Cecílio Filho (2005) obtiveram resultados diferentes em que observaram redução da ATT no híbrido Bônus $\mathrm{N}^{0} 2$ em plantas com dois frutos, comparado a plantas com fixação livre de frutos.

O maior IM em frutos fixados entre o $15^{0}$ e $18^{0}$ nós, comparado aos frutos do $5^{0}$ e $8^{0}$ nós, foi devido à redução da ATT, que elevou a relação SST/ATT e proporcionou incremento na proporção de açúcares em relação a ácidos no fruto. Esta variação na ATT não foi observada em função do número de frutos por planta, que mesmo com maior SST em plantas com apenas um fruto não foi suficiente para alterar o IM. Segundo Villanueva et al. (2004), no meloeiro, as modificações no sabor são devido a alterações nos compostos aromáticos, ácidos orgânicos e açúcares solúveis. Estes autores observaram que o incremento no SST do fruto em estádio mais avançado de maturação proporcionou elevação desta relação e que estes valores podem ser influenciados pelo crescimento do fruto.

De acordo com Villanueva et al. (2004), o acúmulo de açúcar durante o crescimento e desenvolvimento do fruto é de grande importância devido a alta correlação existente entre conteúdo de açúcar e qualidade do fruto. Segundo Valantin Morinson et al. (2006), a competição por assimilados reduziu o SST; Desta forma, o SST que está diretamente relacionado com o conteúdo de açúcar, constitui um bom indicador do adoçamento e, conseqüentemente, da qualidade, quanto ao sabor do fruto, sendo atribuído principalmente à elevação da concentração de sacarose na polpa dos frutos.

A condução da planta com apenas um fruto e sua fixação entre o $15^{\circ}$ e $18^{\circ}$ nós proporcionou maior concentração de AST e ANR. Neste caso, a planta se beneficia da maior AF formada nestas condições em função da ausência de competição com o dreno, favorecendo, assim, o crescimento da parte vegetativa da planta que, posteriormente, contribui com fotoassimilados para os frutos. Observou-se também maior concentração de AR nos frutos fixados entre o $5^{0} \mathrm{e}$ $8^{0}$ nós em razão da menor concentração de ANR nesta posição na planta. Os principais açúcares presentes em melão são a glicose e frutose (AR) e sacarose (ANR). Os açúcares redutores contribuem com quase $100 \%$ do teor de açúcares totais na fase inicial de desenvolvimento dos frutos; todavia, a sacarose pode chegar até $50 \%$ dos açúcares totais na fase final de maturação, com proporção aproximada de $25 \%$ para glicose e $25 \%$ para frutose (Long et al. 2004). O valor obtido para os AST na colheita foi de 83,5 e $79,8 \%$ do SST para plantas conduzidas com um e dois frutos, e de 79,3 e $86,3 \%$ para frutos fixados entre o $5^{0}$ e $8^{0}$ e $15^{0}$ e $18^{0}$ nós, respectivamente.

Desta forma, o suprimento de assimilados, favorecido pela redução do número de frutos por planta e da fixação destes em posições mais elevadas $\left(15^{0} \mathrm{e}\right.$ $18^{0}$ nós), contribui para maior síntese e acumulação de sacarose nos frutos. Isto implica que frutos como o melão, que não têm carboidrato de armazenagem como amido (Hubbard \& Pharr, 1990), deve ser mantido na planta até a maturidade para assegurar adequada qualidade aos frutos na colheita.

Enfim, a redução de frutos na planta de dois para um melhorou a qualidade físico-química desses, mas, reduziu a produtividade da cultura. A fixação de frutos do $15^{0}$ ao $18^{0}$ nó proporcionou frutos maiores em plantas que fixaram um ou dois frutos com incremento na produtividade e qualidade da cultura.

\section{REFERÊNCIAS}

ANDRIOLO JL; FALCÃO LL. 2000. Efeito da poda de folhas sobre a acumulação de matéria seca e sua repartição para os frutos do tomateiro cultivado em ambiente protegido. Revista Brasileira de Agrometeorologia 8: 75-83.

BERTIN N. 1995. Competition for assimilates and fruit position affects fruit set in indeterminate greenhouse tomato. Annals of Botany 75: 55-65.

BERTIN N; GARY C. TCHAMITCHIAN M; VAISSIÉRE BE. 1998. Influence of cultivar, fruit position and seed content in tomato fruit weight during a crop cycle and low and high competition for assimilates. Journal of Horticultural Science \& Biotechnology 73: 541-548.

CASTELLANE PD; ARAUJO JAC. 1994. Cultivo sem solo: hidroponia. Jaboticabal. FUNEP, 43p.

COELHO EV; FONTES PCR; CARDOSO AA. 2003. Qualidade do fruto de melão rendilhado em função de doses de nitrogênio. Bragantia 62: 173-178.
COSTA CC; CECÍlIO FILHO AB; CAVARIANI RL; BARBOSA JC. 2004. Concentração de potássio na solução nutritiva e a qualidade e o número de frutos de melão por planta em hidroponia. Ciência Rural 34: 731-736.

EL KEBLAWY A; LOWETT DOUST J. 1996. Resources re-allocation following fruit removal, patterns in cantaloupe melon. New Phytologist 134: 413-422.

FAGAN EB; MEDEIROS SLP; SIMON J; LUZ GL; BORCIONI E; JASNIEWICZ LR; CASAROLI D; MAFRON PA. 2006. Evolução e partição de massa seca do meloeiro em hidroponia. Acta Siencia Agronomy 28: 165-172.

FURLANI PR; SILVEIRA LCP; BOLONHEZI D; FAQUIN V. 1999. Cultivo hidropônico de plantas. Capinas: IAC, 52p. (Boletim Técnico 180).

HEUVELINK E. 1996. Dry matter partitioning in tomato: validation of dynamic simulation model. Annals of Botany 77: 71-80.

HUBBARD NL; PHARR DM. 1990. Sucrose metabolism in ripening muskmelon fruit as affected by leaf area. Journal American Society Horticultural Science 115: 798802.

KEREN-KEISERMAM A; TANAMI Z; SHOSEYO O; GINZBERG I. 2004. Differing rind characteristic of developing fruit of smooth and netted melons. Journal of Horticulural Science \& Biotechonoly 79: 107-113.

LONG RL; WALSH KB; ROGERS G; MIDMORE DJ. 2004. Source-sink manipulation to increase melon (Cucumis melo L.) fruit biomass and soluble sugar content. Australian Journal of Agricultural Research 55: 1241-1251.

MARTINS SR; PEIL RM; SCHWENGBER JE; ASSIS FN; MENDEZ MEG. 1998. Produção de melão em função de diferentes sistemas de condução de plantas em ambiente protegido. Horticultura Brasileira 16: 24-30.

MARUYAMA WI; BRAZ LT; CECÍLIO FILHO AB. 2000. Condução de melão rendilhado sob cultivo protegido. Horticultura Brasileira 18: 175-179.

MENDLINGER S; PASTENAK D. 1992. Effect of time, salination of flowering, yield and quality factors in melon, Cucumis melo L. Journal of the American Society for Horticultural Science 67: 529-534.

MILLER GL. 1959. Use of dinitrosalicylic acid reagent for determination reducing sugars. Analytical Chemistry 31: 426-428.

MONTEIRO AA; MEXIA JT. 1988. Influência da poda e do número de frutos por planta na qualidade dos frutos e produtividade do melão. Horticultura Brasileira 6: 9-12.

PURQUERIO LFV; CECILIO FILHO AB; BARBOSA JC. 2003. Efeito da concentração de nitrogênio na solução nutritiva e do número de frutos por planta sobre a produção do meloeiro. Horticultura Brasileira 21: 186-191. 
PURQUERIO LFV; CECÍLIO FILHO AB. 2005. Concentração de nitrogênio na solução nutritiva e número de frutos sobre a qualidade de frutos de melão. Horticultura Brasileira 23: 831-836.

SEABRA JÚNIOR S; PANTANO SC; HIDALGO AF; RANGEL MG; CARDOSO AII. 2003. Avaliação do número e posição do fruto de melancia produzidos em ambiente protegido. Horticultura Brasileira 21: 708-711.

SYN GY; HEONG CS; YOO KC. 1991. Effect of temperature, light intensity and fruit setting position on sugar accumulation and fermentation in oriental melon. Journal of Korean Society for Horticultural Science 32: 440-446.
VALANTIN M; GARY C; VAISSIÉRE BE; FROSSARD JS. 1999. Effect of load fruit on partitioning of dry matter and energy in cantaloupe (Cucumis melo L.). Annals of Botany 84: 173-181.

VALANTIN MORINSON M; VAISSIERE BE; GARY C; ROBIN P. 2006. Source-sink balance affects reproductive development and fruit quality in cantaloupe melon (Cucumis melo L.). Journal of Horticultural Science \& Biotechnology 86: 105-117.
VILLANUEVA MJ; TENORIO MD; ESTEBAN MA; MENDONZA MC. 2004. Compositional changes during ripening of two cultivars of muskmelon fruits. Food Chemistry 87: 179-185.

YEMN EW; WILLIS AJ. 1954. The estimation of carbohydrate in plant extracts by anthrote. The Biochemical Journal 57: 505-514. 